\title{
Composición fúngica de bioaerosoles ambientales en corrales
}

\author{
Fungal composition of environmental aerosols in barnyards \\ Natalia Soledad Lanza ${ }^{1,2}$, Carla Paola Bustos ${ }^{1}$, María Jimena Marfil ${ }^{1}$, Nora Guida ${ }^{1}$
}

\section{ReSUMien}

El objetivo del trabajo fue evaluar la micota presente en los corrales de caballos, utilizando la sedimentación simple como método de muestreo. Se trabajó a fines del invierno con 20 muestras provenientes del perímetro de corrales de tierra. Las muestras se obtuvieron colocando placas de Petri con agar Saboureaud $\%$ glucosado suplementado con $0.05 \%$ de penicilina abiertas a 58 y $113 \mathrm{~cm}$ del suelo. Los géneros más representativos en los dos niveles muestreados fueron Cladosporium sp y Sepedonium sp. Se identificaron además, géneros de importancia clínica en equinos como Aspergillus, oportunista ambiental capaz de colonizar los senos paranasales y las bolsas guturales de equinos y producir rinofaringitis, sinusitis y guturitis micótica.

Palabras clave: bioaerosoles; micota ambiental; equinos

\section{Abstract}

The aim of this work was to evaluate the fungus present in horse corrals, using simple sedimentation as a sampling method. This was done at the end of winter collecting 20 samples from the perimeter of corrals. Samples were obtained by placing Petri dishes with Saboureaud agar $2 \%$ glucose supplemented with $0.05 \%$ penicillin open at 58 and 113 $\mathrm{cm}$ above the ground. The most representative genus in the two sampled levels were Cladosporium sp and Sepedonium sp. It was also identified genus of clinical importance in equines such as Aspergillus, environmental opportunist able to colonize the paranasal sinuses and guttural bags of horses and produce rhinopharyngitis, sinusitis and fungal guturitis.

Key words: bioaerosols; environmental micota; horses

\footnotetext{
${ }^{1}$ Cátedra Enfermedades Infecciosas, Facultad de Ciencias Veterinarias, Universidad de Buenos Aires, Argentina

${ }^{2}$ E-mail: nlanza@fvet.uba.ar
}

El trabajo fue subsidiado por la Universidad de Buenos Aires: Proyecto de Investigación UBACyT 20020130100299BA

Recibido: 21 de marzo de 2018

Aceptado para publicación: 30 de septiembre de 2018 


\section{INTRODUCCIÓN}

Los hongos residentes de la mucosa respiratoria de los animales, especialmente herbívoros, provienen del medio ambiente y pueden también ser vehiculizados por el alimento. Así, el aire inspirado transporta esporas de hongos miceliares ambientales y patógenos en forma de bioaerosoles, conformando la micota transitoria o permanente de la mucosa respiratoria de los animales. Es importante considerar que la contaminación del aire inspirado puede ser causa de enfermedades respiratorias al actuar como vehículo de bacterias, virus y hongos patógenos u oportunistas, así como causal de reacciones de hipersensibilidad (De La Rosa et al., 2002; Krysiñska-Traczyk et al., 2004; Nardoni et al., 2005; Castañeda et al., 2006; Morán et al., 2009). Por lo tanto, el conocimiento de hongos y bacterias que forman parte de la ecobiota de las mucosas junto con el conocimiento del bioma en el que habitan puede ser una herramienta interesante para la interpretación diagnóstica de cultivos.

En estudios previos realizados en el Laboratorio Escuela de Enfermedades Infecciosas de la Facultad de Ciencias Veterinarias de la Universidad de Buenos Aires, se analizó la composición fúngica cultivable del aire espirado por equinos (Bustos et al., 2011) y la micota residente en nasofaringe (Mesplet et al., 2005; Guida et al., 2008) hallándose hongos de diversos géneros: Aspergillus sp, Penicillium sp, Cladosporium sp, Alternaria sp y Mucor sp. Así mismo, hongos cultivables residentes en nasofaringe demostraron una micota abundante y variada de hongos miceliares del género Aspergillus sp, Penicillium sp, Alternaria sp, Mucor sp, Cladosporium sp, Absidia sp, Exophiala sp, Acremonium sp, Curvularia sp, Dreschslera sp, Fusarium sp, Geotrichum sp, Rhizopus $\mathrm{sp}$, Scopularium sp, Ucladium sp y Verticillium sp (Mesplet et al., 2005; Guida et al., 2008; Bustos et al., 2011; Guida et al., 2012). Los géneros identificados en el aire espirado también fueron encontrados en la nasofaringe de los caballos estudiados y se podría presumir que los animales podrían vehiculizar microorganismos residentes de cavidad nasal, o provenientes del ambiente.

Con base a estos antecedentes, el presente estudio tuvo como objetivo evaluar la micota de corrales donde habitan animales de la Facultad de Ciencias Veterinarias de la Universidad de Buenos Aires, Argentina.

\section{Materiales y Métodos}

Tomando en consideración la dificultad de recoger y evaluar todos los componentes de los bioaerosoles utilizando un único método de muestreo, y que existen métodos de diferente complejidad y utilidad, en el presente estudio se utilizó la sedimentación simple (Borrego et al., 2010), por su facilidad en la técnica de muestreo y no requerir instrumentos específicos, ya que las partículas se depositan por gravedad.

Los caballos se encontraban en corrales de tierra, un área aproximada de $1730 \mathrm{~m}^{2}$, habitada por cuatro equinos en convivencia directa con tres bovinos, y eran alimentados con fardo. Así mismo, había presencia de felinos de vida libre en el predio. Las muestras se tomaron del perímetro de los corrales entre fines de agosto e inicios de septiembre de 2014, con una temperatura ambiental promedio de $15-17^{\circ} \mathrm{C}$ y una humedad máxima promedio de $80 \%$, época que corresponde a la parte final del invierno.

Los muestreos fueron realizados por la tarde, en días de sol y con poco o nulo viento, para que no afecte la técnica elegida. Las muestras se obtuvieron colocando placas de Petri abiertas con agar Saboureaud 2\% glucosado (Britania ${ }^{\circledR}$, Argentina) suplementado con $0.05 \%$ de penicilina, a 58 y $113 \mathrm{~cm}$ del suelo (Figura 1), a una distancia aproximada de $5 \mathrm{~m}$ entre sí, abarcando de esta manera todo el lateral accesible del corral en estudio. Las placas estuvieron expuestas 


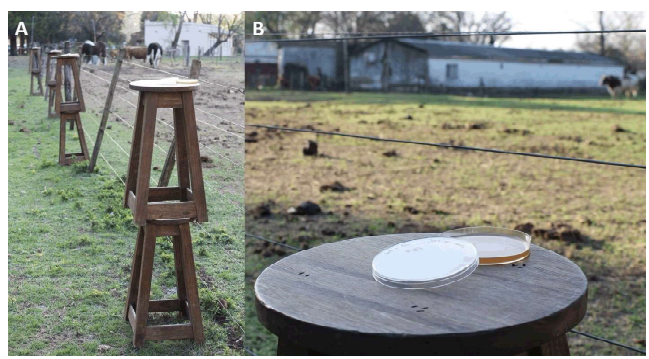

Figura 1. Metodología de muestreo por sedimentación simple del perímetro de los corrales. A. Muestreo a $113 \mathrm{~cm}$ de altura. B. mayor detalle placa de Petri con agar Saboureaud expuesta al aire ambiental a $58 \mathrm{~cm}$ de altura

durante $20 \mathrm{~min}$ al aire ambiental, y posteriormente se cerraron y se trasladaron al laboratorio.

Las placas fueron incubadas a $25-28{ }^{\circ} \mathrm{C}$ hasta observar crecimiento de hongos miceliares y por un tiempo máximo de 30 días. Se estudiaron las características macroscópicas de las colonias teniendo en cuenta el color de la colonia del reverso y el anverso, aspecto y consistencia, y se registró el número de Unidades Formadoras de Colonias (UFC) por placa. Posteriormente, se observaron microscópicamente mediante la coloración de azul de lactofenol para la identificación de los géneros de los hongos que presentaron órganos de reproducción asexual (Zapater, 1965; Gené y Guarro, 2001). En aquellos donde no se identificó reproducción asexual fueron considerados como 'no fructificados' y se los resembró en medio Agar Papa Glucosado (Britania ${ }^{\circledR}$, Argentina), favoreciendo el desarrollo exuberante y la esporulación de hongos en general. Aquellos que tampoco presentaron órganos de reproducción asexual en estos subcultivos fueron considerados como 'no identificables'.

\section{Resultados y Discusión}

El recuento de células viables expresado en UFC/placa para los niveles de 58 y 113 $\mathrm{cm}$ de altura se detallan en los cuadros 1 y 2 .
El género más representativo en los dos niveles fue Cladosporium sp. Estos resultados coinciden con Colman et al. (2011) que describen la predominancia de este género en el medio ambiente de la Provincia de Buenos Aires, Argentina. Hongos de este género son hallados con frecuencia en cultivos obtenidos de hisopados nasofaríngeos (Mesplet et al., 2005; Guida et al., 2008) y su relación con la micota hallada en el ambiente puede colaborar en la interpretación de los hallazgos en el laboratorio de diagnóstico.

Es interesante mencionar la identificación de algunas UFC de Aspergillus sp por su relevancia en la salud animal, debido a que es un ambiental oportunista capaz de colonizar los senos paranasales y las bolsas guturales de equinos y producir rinofaringitis, sinusitis y guturitis micótica (Ferro et al., 2000; Guida et al., 2005, 2008; Morán et al., 2009). Debido a que este hongo puede ingresar por vía respiratoria (Nardoni et al., 2005), es relevante mencionar que fue hallado en ambos niveles de altura y, por lo tanto, podría ser fácilmente inspirado por los animales mediante bioaerosoles.

Otros géneros encontrados en ambos niveles de altura fueron Penicillium sp, Mucor sp, Fusarium sp y Alternaria sp, los cuales son frecuentemente aislados tanto de cultivos de aire espirado como de muestras de nasofaringe de caballos (Bustos et al., 2013). El ingreso nasal de agentes micóticos por medio de bioaerosoles puede ser relevante si se tiene en cuenta que pueden desencadenar respuestas de hipersensibilidad tipo I o tipo III (Zaror et al., 1999; Morán et al., 2009) que comprometan la salud de los animales.

Por otro lado, se debe considerar que los factores climáticos son altamente influyentes en la composición de la micota ambiental. Los resultados obtenidos, entonces, corresponden al estado climático de ese momento (templado y ventoso) y podrían verse afectados por las diferentes épocas del año en las que se realice el muestreo, así como por la velocidad del viento, humedad y temperatura (Nitiu y Mallo, 2011; Ruiz et al., 2014). 
Cuadro 1. Recuento de células viables colectadas a $58 \mathrm{~cm}$ de altura en el perímetro de corrales de caballos y obtenidos en los cultivos de Agar Saboureaud y Agar Papa Glucosado, expresado en UFC/placa (Buenos Aires, Argentina)

\begin{tabular}{lccccccccccc}
\hline \multirow{2}{*}{ Género } & \multicolumn{10}{c}{ Muestras } & \multirow{2}{*}{ Total } \\
\cline { 2 - 10 } & 1 & 2 & 3 & 4 & 5 & 6 & 7 & 8 & 9 & 10 & \\
\hline Cladosporium sp & 12 & 3 & 3 & 9 & 5 & 6 & 2 & - & 4 & 4 & 48 \\
Sepedonium sp & - & 3 & 4 & 2 & 3 & - & 1 & 3 & 4 & 4 & 24 \\
Trichothecium $\mathrm{sp}$ & 2 & 1 & - & 3 & 3 & 1 & 3 & - & - & 4 & 17 \\
Mucor $\mathrm{sp}$ & - & - & - & 2 & - & - & - & - & - & 1 & 3 \\
Fusarium $\mathrm{sp}$ & - & - & - & 1 & - & 2 & - & - & 3 & 3 & 9 \\
Gliocladium $\mathrm{sp}$ & 1 & - & - & - & 1 & 1 & - & - & 2 & 1 & 6 \\
Alternaria $\mathrm{sp}$ & 1 & 1 & - & - & - & - & - & - & - & - & 2 \\
Scopularium $\mathrm{sp}$ & - & - & - & - & 1 & 3 & - & 1 & 1 & 3 & 9 \\
Penicillium $\mathrm{sp}$ & 5 & 2 & - & - & - & - & - & - & - & - & 7 \\
Aspergillus sp & - & - & - & - & - & - & - & 3 & - & - & 3 \\
Acremonium $\mathrm{sp}$ & - & - & - & - & - & - & - & 3 & 1 & - & 4 \\
Phialophora $\mathrm{sp}$ & - & - & - & - & - & - & - & 1 & 1 & - & 2 \\
No identificables & - & - & 5 & - & 4 & 1 & 7 & 1 & - & - & 18 \\
\hline Total & 21 & 10 & 12 & 17 & 17 & 14 & 13 & 12 & 16 & 20 & 152 \\
\hline
\end{tabular}

Cuadro 2. Recuento de células viables colectadas a $113 \mathrm{~cm}$ de altura en el perímetro de corrales de caballos y obtenidos en los cultivos de Agar Saboureaud y Agar Papa Glucosado, expresado en UFC/placa (Buenos Aires, Argentina)

\begin{tabular}{lccccccccccc}
\hline \multirow{2}{*}{ Género } & \multicolumn{1}{c}{ Muestras } & \multirow{2}{*}{ Total } \\
\cline { 2 - 9 } & 1 & 2 & 3 & 4 & 5 & 6 & 7 & 8 & 9 & 10 & \\
\hline Cladosporium sp & 4 & 2 & 5 & 9 & 1 & 5 & 8 & 4 & 2 & 4 & 44 \\
Sepedonium sp & 2 & 1 & 1 & 3 & 2 & 1 & 1 & - & 5 & 3 & 19 \\
Trichothecium $\mathrm{sp}$ & 2 & 1 & - & - & 1 & - & - & 2 & - & - & 6 \\
Fusarium sp & - & - & 2 & - & - & - & - & - & - & - & 2 \\
Mucor sp & - & - & - & - & - & 3 & - & 1 & - & - & 4 \\
Rhizopus $\mathrm{sp}$ & - & - & - & - & - & 1 & - & - & 1 & - & 2 \\
Aspergillus $\mathrm{sp}$ & 1 & 1 & - & - & - & 1 & - & - & - & - & 3 \\
Penicillium $\mathrm{sp}$ & - & - & 1 & 1 & - & - & - & - & - & - & 2 \\
Nigrospora $\mathrm{sp}$ & - & 1 & - & - & - & - & - & - & - & - & 1 \\
Malbranchea $\mathrm{sp}$ & - & 1 & - & - & - & - & - & - & - & - & 1 \\
Alternaria $\mathrm{sp}$ & - & - & - & 1 & 1 & - & - & - & - & - & 2 \\
Gliocladium $\mathrm{sp}$ & - & - & - & - & 1 & - & - & - & - & - & 1 \\
Geotrichum $\mathrm{sp}$ & - & - & - & - & - & - & - & 3 & - & - & 3 \\
Acremonium $\mathrm{sp}$ & - & - & - & - & - & 1 & - & - & - & - & 1 \\
No identificables & - & 1 & 3 & - & 1 & 4 & 3 & 6 & 6 & 5 & 29 \\
\hline Total & 9 & 8 & 12 & 14 & 7 & 16 & 12 & 16 & 14 & 12 & 120 \\
\hline
\end{tabular}


Este trabajo constituye un estudio preliminar, por lo que se espera poder aumentar el número de muestras y ampliar el muestreo a las estaciones del año para poder hacer un análisis más profundo de los bioaerosoles ambientales.

\section{Literatura Citada}

1. Borrego S, Perdomo I, Guiamet P, Gómez S. 2010. Estudio de la concentración microbiana del aire en depósitos del Archivo Nacional de Cuba. AUGMDOMUS 1: 118-137.

2. Bustos C, Etchecopaz A, Muñoz A, Mesplet M, Guida N, et al. 2013. Bacteria and fungi isolated from nasopharynx of horses as a reservoir of bioaerosols. II International Congress on Pathogens at the Human Animal Interface (ICOPHAI). Porto de Galinhas, Brazil.

3. Bustos C, Etchecopaz A, Salas J, Muñoz A, Guida N. 2011. Estudio de la calidad fúngica del aire espirado por equinos y su rol como reservorio de bioaerosoles. XII Congreso Argentino de Micología. Posadas, Argentina.

4. Castañeda REI, Morales PM, Avelino FF, Chávez BE, Espinosa TA, Morales TE. 2006. Cuantificación de bioaerosoles en las áreas de proceso de una industria zapatera poblana y su relación con la salud de los trabajadores. Enf Infec Microbiol 26(1). [Internet]. Disponible en: http://www.medigraphic.com/pdfs/micro/ei-2006/ei061d.pdf

5. Colman E, Müller A, Lespade P, Aguilar M, Matamoros N, Schlink U, Massolo L, et al. 2011. Calidad del aire (COVs, MCOVs y mohos) en áreas urbanas e industriales de la Región Capital de la Provincia de Buenos Aires, Argentina. Ciencia 6: 81-95.

6. de la Rosa MC, Mosso MA, Ullán C. 2002. El aire: hábitat y medio de transmisión de microorganismos. Observatorio Medioambiental 5: 375-402.
7. Ferro E, Ferrucci F, Salimei E, Antonini M, Codazza D, Caniatti M. 2000. Relationship between the conditions of lower airways in healthy horses, environmental factors and air quality in stables. Pferdeheilkunde 16: 579-586. doi: 10.21836/PEM20000603

8. Gené G, Guarro J. 2001. Identificación de otros hongos miceliares. En: Pemán J, Martín-Mazuelos E, Calvo MCR (eds). Guía práctica de identificación y diagnóstico en micología clínica. Rev Iberoam Micol. [Internet]. Disponible en: http://www.guia.reviberoammicol.com/ Capitulo13.pdf

9. Guida N, Mesplet M, Di Gennaro E, Digilio P, Moras EV. 2005. Presencia de Aspergillus fumigatus en la cavidad nasofaríngea de equinos. Rev Iberoam Micol 22: 160-162. doi: 10.1016/S11301406(05)70031-0

10. Guida N, Bustos C, Muñoz A, Gonzales S, Etchecopaz A. 2012. Bioaerosols: study of the bacteria and the fungical quality of the exhaled air by equine. Mycoses 55(Suppl 4): 144-145.

11. Guida N, Mesplet M, Muñoz M, Digennaro E, Martínez M, Moras E, Barboni A. 2008. Evaluación de la microbiota nasofaríngea en caballos clínicamente sanos. Vet Arg 25: 741-748

12. Krysiñska-Traczyk E, Skorska C, Prämo Z, Sitkowska J, Cholewa G, Dutkiewicz J. 2004. Exposure to airborne microorganisms, dust and endotoxin during flax scutching on farms. Ann Agr Env Med 11: 309-317.

13. Mesplet M, Guida N, Digennaro E, Bacigalupe A, Barboni A, Moras E. 2005. Micota de cavidad nasofaríngea de los equinos. Vet Arg 22: 423-428.

14. Morán G, Araya O, Ortloff A, Folch H. 2009. Características citológicas del lavado bronqueoalveolar y respuesta inmune humoral frente a Aspergillus fumigatus en caballos Chilotes con obstrucción recurrente de las vías aéreas. Arch Med Vet 41: 83-88. doi: 10.4067/ S0301-732X2009000100012 
15. Nardoni S, Mancianti F, Sgorbini M, Taccini F, Corazza M. 2005. Identification and seasonal distribution of airborne fungi in three horse stables in Italy. Mycopathologia 160: 29-34. doi: 10.1007/s11046-005-2669-3

16. Nitiu DS, Mallo AC. 2011. Variaciones en la estacionalidad de polen y es poras fúngicas en la atmósfera de la ciudad de La Plata (Argentina). B Soc Argent Bot 46: 297-304

17. Ruiz M, Barbero T, Mattos M, Decarlini M, Peralta N, Rustan M. 2014. Identificación de hongos anemófilos en campus de la Universidad Católica de Córdoba. XIII Congreso Argentino de Micología. Córdoba, Argentina.

18. Zapater R. 1967. Atlas de diagnóstico micológico. Buenos Aires, Argentina: El Ateneo Editorial. $253 \mathrm{p}$.

19. Zaror L, Araya O, Varela C. 1999. Determinación de hongos y bacterias termofílicas en heno y paja en criaderos de caballos criollos chilenos. Arch Med Vet 31: 119-124. doi: 10.4067/S0301732X1999000100013 